\title{
Comparative Evaluation of Electrostatic Sprayer for Cotton Crop
}

\author{
Bharat Patel*, Manjeet Singh, P. K. Mishra, G. S. Manes, Karun Sharma and Abhinab Mishra \\ Dept. of Farm Machinery \& Power Engineering, PAU, Ludhiana, Punjab (141 004), India
}

\section{Article History}

Manuscript No. AR1458

Received in $9^{\text {th }}$ September, 2015

Received in revised form $18^{\text {th }}$ July, 2016

Accepted in final form $7^{\text {th }}$ September, 2016

\section{Correspondence to}

"E-mail: bharat-coaefpm@pau.edu

\section{Keywords}

Electrostatic sprayer, droplet density, spray deposition

\begin{abstract}
A comparative evaluation of an electrostatic sprayer (make ESS) was conducted at Krishi VigyanKendra, Faridkot, Punjab, India. Effect of electrostatic spraying on droplet density, area coverage, spray deposition, uniformity coefficient, droplet size and bio-efficacy were observed and comparison was made between different types of sprayer i.e. electrostatic sprayer, lever operated knapsack sprayer, power operated knapsack sprayer and tractor operated gun type sprayer. It was found that on an average droplet density by electrostatic sprayer was significantly $(p=0.0000017) 47.19,68.07$ and $78.26 \%$ higher than that of TOG, POK and LOK sprayers respectively. It was found that maximum number of droplets, for electrostatic sprayer was 42 at 48.61 $\mu$, for POK sprayer 10 at $98.68 \mu$, for LOK sprayer 11 at $98.68 \mu$ and TOG sprayer 12 at $125.00 \mu$. Percentage area covered by droplets on average over the plant (top, middle and bottom leaves of plant) was significantly $(p=0.012) 34.69,24.42$ and $69.25 \%$ higher than of POK sprayer, LOK sprayer and TOG sprayer respectively. The volume of spray deposition on leaves was significantly $(p=0.022) 50.20,44.42$ and $62.63 \%$ lesser than TOG, POK and LOK respectively. On an average bio-efficacy of electrostatic sprayer was more $(47.75,59.47$ and $26.57 \%)$ than other three sprayers viz. POK, LOK and TOG sprayers respectively.
\end{abstract}

\section{Introduction}

Cotton is an important commercial crop of India; having 11.55 mha cultivated area (largest in the world). The yield is only $552 \mathrm{~kg} \mathrm{ha}^{-1}$ (CCI, 2014) as against the world average of $758 \mathrm{~kg} \mathrm{ha}^{-1}$ (USDA, 2014). One of the reason for this lower yield is poor control of insect and pest. An estimated 37\% of all crop production is lost annually to pests ( $13 \%$ to insects, $12 \%$ to plant pathogens, and $12 \%$ to weeds) in spite of the use of pesticides and non-chemical controls (Pimentel and Levitan, 1986). Overall, the losses increased from $7.2 \%$ in early 1960 s to $23.3 \%$ in early 2000 s. The maximum increase in loss occurred in cotton (18.0 to $50.0 \%$ ), followed by other crops like sorghum and millets ( 3.5 to $30.0 \%$ ), maize (5.0 to $25.0 \%$ ) and oilseeds (other than groundnut) (5.0 to $25.0 \%$ ) (Dhaliwal et al., 2010).

Several methods of spraying are available to protect the crops from diseases. On the basis of volume application rate there are three types of sprays high volume spray, low volume spray and ultra low volume spray. The high volume sprayer leads to spray loss to due to larger size of droplets and more volume application rate, and the low volume sprayer considerably increase the bio-efficacy by better deposition but it predominant to spray drift. The third method comes in optimum range of droplet size to enhance comparatively better deposition and bio-efficacy but there is no control over drift which leads to environmental pollution and chemical loss (Piche et al., 2000).

The problem of over dosage of pesticide is common in most countries and its application leads to many problems such as chemical waste and environmental pollution from spray drift. There have been many approaches to reduce the amount of pesticide applied in agricultural spray. Small-scale farmers usually apply dilute pesticide solution using a knapsack sprayer with a hydraulic nozzle. This method is simple but has several disadvantages. Spray distribution is poor and labour cost is high. Farmers also used air assisted sprayer which produce smaller droplet size but due to lack of control, lot of chemical was wasted by drift. Ninety five percent of the chemical applied can be wasted to the ground (GrahamBryce, 1977) or at most $50 \%$ of mass transfer on the desired plant (Pimentel and Levitan, 1986).

The recent concept of spraying is to spray the target pest more efficiently by selecting optimum droplet size and density for maximum retention and coverage. Entomologist 
suggested that optimum droplet size for maximum retention with an aqueous solution is to be $100 \mathrm{~mm}$ or less and such a reduction in droplet size would also improve coverage due to an increase in the number of droplets at the same volume application rate Thus, if drift is not a problem, a decrease in droplet size increases retention and coverage (Heijne, 1980).

Electrostatic sprayer works on the principle of Coulomb's Law that opposite charges attract each other and due to the effect of induction an opposite charge is induced on target. The charged spray droplets are attracted by the positively charged leaf surface. The charged spray droplets move upward and underside of the leaf surface. Once the leaf has been adequately covered in spray material, the positive charge on the leaf dissipates allowing other droplets to find places in the canopy that have not been covered. There are three methods of charging pesticides i.e. induction charging, ionized charging (corona charging), and direct charging (contact charging or conduction charging). Out of the various liquid charging methods, the induction charging approach has appeared to be more convenient and practical for the electrification of aqueous pesticides. In induction charging, the grounded spray liquid stays near high voltage electrode for sufficient time so that opposite charges are induced on the spray droplets. Electrostatic sprayers work ideal lyon dense and broad leafy crops like cotton, soyabean, etc. (Singh et al., 2013).

\section{Materials and Methods}

A trial for evaluation of electrostatic sprayer with three different locally used sprayers was conducted on cotton crop at the Research Farm of Regional Research Station, Faridkot Punjab, India during kharif season of 2013 on $14^{\text {th }}$ October. The crop geometry was as row to row and plant to plant spacing for the crop were 90 and $75 \mathrm{~cm}$ respectively.

\subsection{Description of sprayers used in study}

There were four sprayer used in this study viz. Mobile backpack electrostatic sprayer, Tractor operated gun type sprayer, Power operated hydraulic backpack sprayer and lever operated hydraulic backpack sprayer. Main specifications of selected sprayers are given in (Table 1). The Mobile Backpack (MBP) electrostatic sprayer (ESS, Make: USA) isan air assisted sprayer equipped with a $6.5 \mathrm{Hp}$ petrol engine to produce air pressure ranging from $4.2-4.9 \mathrm{~kg} \mathrm{~cm}^{-2}$, requires for atomization and conveying of spray droplets to the target plants. The range of spray is from 3.5 to $4.5 \mathrm{~m}$. The discharge rate of nozzle is $0.11-0.16 \mathrm{~lm}^{-1}$. There is an electrode at the orifice of nozzle connected to dc battery and a compact electrostatic circuit which is supplies sufficient voltage for charging the drops. There is a $50 \mathrm{~m}$ long flexible and durable airline tube provided for spraying in interior of field. The
Table 1: Technical specifications of the sprayer used for the trial

\begin{tabular}{lcccc}
\hline Specifications & ESS & TOG & POK & LOK \\
\hline Power source & 6.5 & Tractor & Petrol & Manual \\
& Hp & $>35 \mathrm{Hp}$ & engine & \\
Operating pressure & $4.2-$ & $10-$ & $1-$ & $3.5-$ \\
$\left(\mathrm{kg} \mathrm{cm}^{-2}\right)$ & 4.9 & 25 & 2 & 4.5 \\
Tank capacity, 1 & 15 & 500 & 15 & 15 \\
Nozzle discharge & $0.11-$ & $4.75-$ & $0.56-$ & $0.90-$ \\
$\left(\mathrm{l} \mathrm{m}^{-1}\right)$ & 0.16 & 4.90 & 0.62 & 0.92 \\
Hose pipe length (m) & 30 & 300 & 1 & 1 \\
No. of nozzles & 1 & 1 & 1 & 1 \\
\hline
\end{tabular}

tractor operated gun type sprayer (TOG) is a three point hitch sprayer equipped with a water tank of capacity 5001 , spray gun having discharge in the range of $0.45 \mathrm{l} \mathrm{m}^{-1}$ to 0.60 $1 \mathrm{~m}^{-1}$. It equipped with a PTO driven hydraulic pump which is produces liquid pressure of $10-25 \mathrm{~kg} \mathrm{~cm}^{-2}$ for atomization of spray. The length of water line tube is about $300 \mathrm{~m}$. The discharge rate is $4.75-4.91 \mathrm{~m}^{-1}$. The power operated knapsack sprayer (POK) is equipped with of 151 water tank; operating pressure is ranges from $1-2 \mathrm{~kg} \mathrm{~cm}^{-2}$ for atomization of spray. The nozzle discharge rate is ranges from $0.560-0.6201 \mathrm{~m}^{-1}$. Lever Operated knapsack sprayer (LOK) (Make ASPEE) equipped with a 151 water tank, produces hydraulic pressure in rage of 3.5-4.5 kg cm-2 with discharge rate of $0.900-0.920$ $1 \mathrm{~m}^{-1}$ (Narang et al., 2015a).

\subsection{Field evaluation protocols}

Evaluation of the sprayer was done at 75 Days after sowing of the crop, when there was full coverage of the ground by plant canopy and it was ensure that the whitefly populations was above ETL (Economic Threshold Limit). Various sprayer performance parameters were recorded during the spraying (Plate 1) of all four sprayers. Performance of electrostatic sprayerwas compared with tractor operated gun sprayer, poweroperated knapsack sprayer and lever operated hydraulic knapsack sprayer and discussion was made. The bio efficacy of sprayers against insect mortality was done by monitoring whitefly population before the spray at interval of 3, 7 and 15 DAS (Days after spraying).

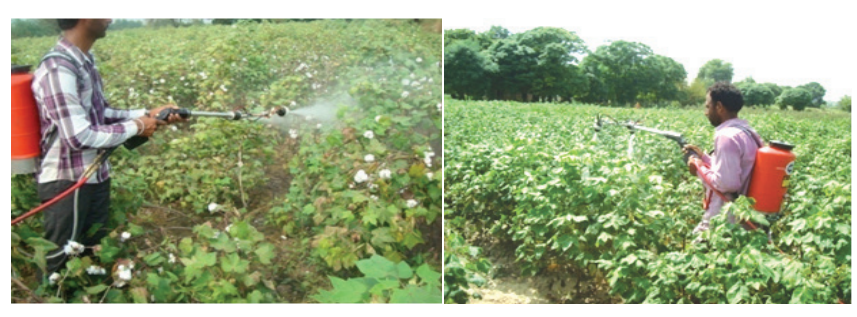

Plate 1: View of electrostatic spraying on cotton crop 


\subsection{Measurement of spray parameters}

The different spray parameters determined were Number Median Diameter (NMD), Volume Median Diameter (VMD), uniformity coefficient (UC), droplets density (no. of droplets $\left.\mathrm{cm}^{-2}\right)$, droplet size, area covered by droplets $\left(\mathrm{mm}^{2} \mathrm{~cm}^{-2}\right)$ and volume of spray deposition $\left(\mathrm{cc} \mathrm{cm}^{-2}\right)$.

To determine the above parameters water-sensitive papers (cards $26 \times 76 \mathrm{~mm}^{2}$ ) were attached on the upper and under side of the leaves at three different heights of cotton canopy (Top, middle and bottom) (Plate 2). After the spray, cards were collected and placed into Zip-Lock ${ }^{\circledR}$ bags. The cards were analyzed for percentages of card area covered with spay patches. Spray coverage and size distribution of spots on the cards were determined by using droplet analyzing system (Mishra et al., 2012).

A droplet analyzing system was used for analyzing the spray images. It consisted of a microscope, CCD camera, PC with droplet analyzing software (USB digital scale) and a monitor.

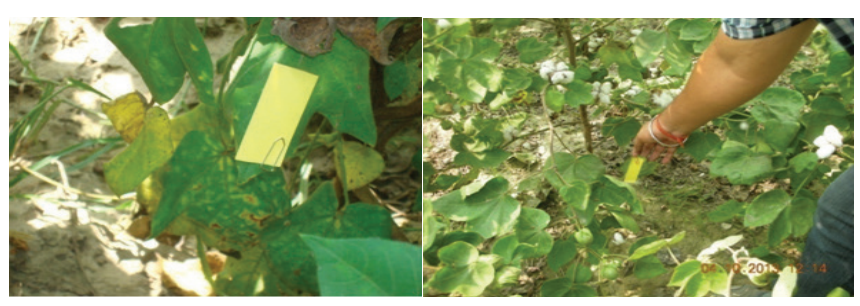

Plate 2: Location of water sensitive papers

The results were analyzed and compared for difference of means of all spray parameters of respective sprayers. The comparison was made on the basis of statistics analysis of spray parameter using a statistical tool SPSS.

\subsection{Bio-efficacy of sprayer}

Bio-efficacy is a measure of pest mortality and diseases control. The bio-efficacy is determined by counting number of pestson randomly selected plants in the field. In this experiment spraying trials of the four sprayers (ESS, TOG, POK and LOK) were conducted on field plots of $50 \times 20 \mathrm{~m}^{2}$ for each sprayer with insecticide Sutathion @ $6001 \mathrm{acre}^{-1}$. For whitefly populations in cotton plants at least 10 plants randomly selected (Narang et al., 2015b) and tagged for further observations. The relative abundance whitefly was recorded from underside of three fully formed leaves of the upper canopy before 10 am at interval of 3, 7, 15 days after spray (Shera et al., 2015).

\section{Results and Discussion}

3.1. Number median diameter (NMD) volume median diameter (VMD) and uniformity coefficient (UC)

It was observed that average value of number median diameter for $\operatorname{ESS}(24.48 \mu \mathrm{m})$ was significantly $(p=0.00091)$ less as compared to TOG sprayer $(74.26 \mu \mathrm{m})$, POK sprayer $(73.47$ $\mu \mathrm{m})$ and LOK sprayer $(69.85 \mu \mathrm{m})$. It was also observed that average value of volume median diameter for ESS (45.28 $\mu \mathrm{m})$ was significantly ( $p=0.00006$ ) less as compared to TOG sprayer $(132.93 \mu \mathrm{m})$, POK sprayer $(144.39 \mu \mathrm{m})$ and LOK sprayer $(134.33 \mu \mathrm{m})$. The results revealed that average value of uniformity coefficient (VMD/NMD) for ESS (2.00) was significantly $(p=0.001)$ less as compared to TOG sprayer (2.29), POK sprayer (3.86) and LOK sprayer (3.57). It means spray was comparatively more uniform by ESS than other sprayers. As the droplet size becomes more uniform, the uniformity coefficient becomes nearer to unity (Singh, 2005). The smaller diameter (NMD and VMD) was because of the pressurized air atomization, comparatively low volume flow rate of liquid and electrostatic force. The electrostatic effect avoid the collision of suspended charged spray droplets to become bigger droplet and hence the diameter of spray droplets was less affected (lesser uniformity coefficient) after the charging of the spray as compared to the other nonelectrostatic sprayers.

\subsection{Droplet density and size}

\subsubsection{Droplet density}

The results of droplet density measured by water sensitive paper are shown in (Figure 1). The droplet density measured in the laboratory on the upper side of top, middle and bottom leaves were 344,323 and 301 droplets $\mathrm{cm}^{-2}$ respectively for the ESS. The droplet densities on top, middle and bottom canopy were $80.51,74.25$ and 56.15 droplets $\mathrm{cm}^{-2}$ for LOK sprayer, 120, 100 and 89 droplets $\mathrm{cm}^{-2}$ for POK sprayer, 202, 165 and 145 droplets $\mathrm{cm}^{-2}$ for TOG sprayer respectively. The overall results revealed that on an average, droplet density on the canopy by ESS was significantly ( $p=0.0000017)$ higher i.e. $47.19,68.07$ and $78.26 \%$ than TOG, POK and LOK sprayer respectively at $5 \%$ level of significance.

\subsubsection{Droplet size}

Sprayer performance based upon the droplet size on water sensitive paper is depicted in (Figure 2) and it is visible that the maximum droplets, i.e. 42 numbers were of size 48.61 $\mu$ for the ESS, 10 numbers were of size $98.68 \mu$ for POK sprayer, 11 numbers were of size $98.68 \mu$ for LOK sprayer and 12 numbers were of size $125.00 \mu$ for the TOG sprayer were observed. The droplet size of $99 \%$ droplets were below $150 \mu$ for ESS, but in case of other sprayer it was $179.35 \mu$ for POK sprayer, $2010.00 \mu$ for LOK sprayer and $190.22 \mu$ for TOG sprayer respectively.

\subsubsection{Area covered by droplets}

The results of area covered by droplets measured by water sensitive paper are depicted in (Figure 3 ). The area covered by droplets measured in the laboratory for the treatments on the 


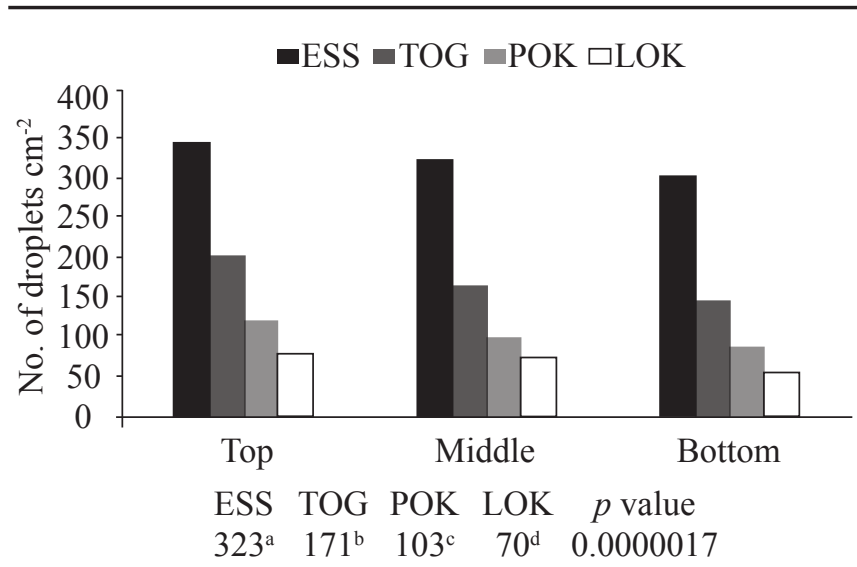

Figure 1: Droplet density on water sensitive paper

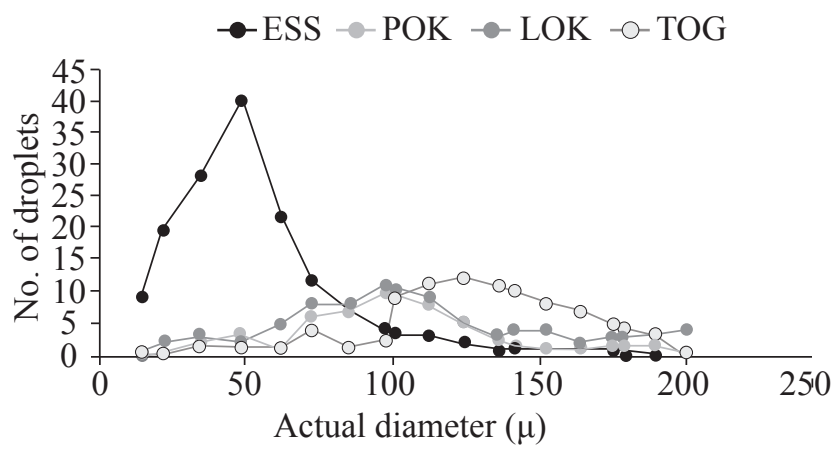

Figure 2: Sprayer performances in water sensitive paper

upper side of the leaves at the top, middle and bottom levels of the plant and it was found that for ESS the area covered was $14.25,11.56$ and $9.75 \mathrm{~mm}^{2} \mathrm{~cm}^{-2}$ respectively. The area covered by droplets at top, middle and bottom levels of the plant for TOG sprayer were $9.45,7.52$ and $3.41 \mathrm{~mm}^{2} \mathrm{~cm}^{-2}$ respectively. The area covered by droplets for POK sprayer were $8.52,5.46$ and $2.65 \mathrm{~mm}^{2} \mathrm{~cm}^{-2}$ at the top, middle and bottom levels of the plant respectively, and in case of LOK

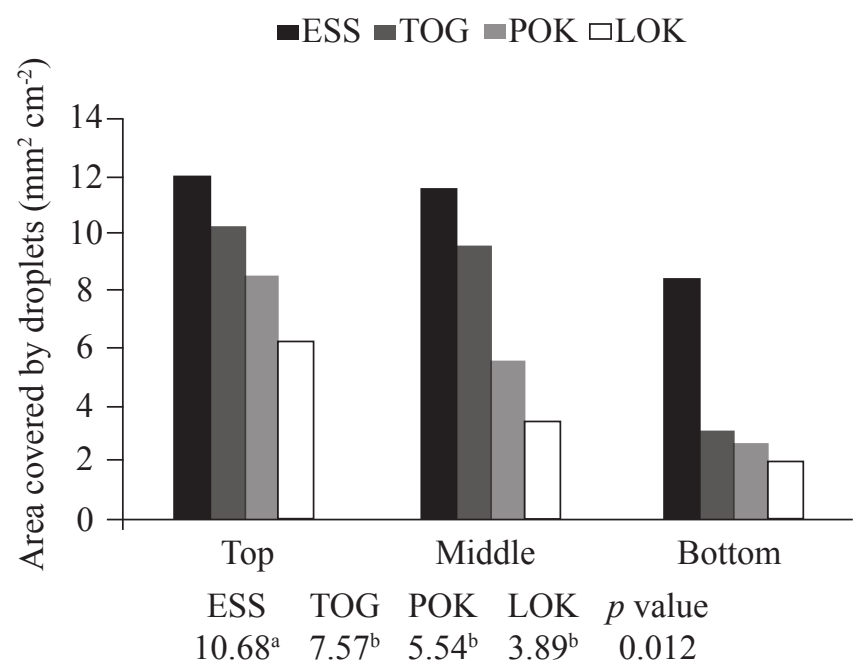

Figure 3: Area covered by droplets sprayer the area covered were $6.21,3.45$ and $2.00 \mathrm{~mm}^{2} \mathrm{~cm}^{-2}$ at the at top, middle and bottom levels of the plant respectively. The overall results revealed that area covered by droplets on in case of ESS was significantly ( $p=0.012$ ) higher 44.55 , 55.26 and $68.68 \%$ more than TOG sprayer, POK sprayer and LOK sprayer at top middle and bottom leaves of plant canopy respectively at $5 \%$ level of significance.

\subsubsection{Volume of spray deposition}

The results of volume of spray deposition of two types of nozzles measured by water sensitive paper are depicted in (Figure 4). The volume of spray deposition $\left(\times 10^{-6} \mathrm{cc} \mathrm{cm}^{-2}\right)$ measured in the laboratory on the upper side of the leaves at the top, middle and bottom levels of the plant were 82.50, 64.50 and $45.30 \times 10^{-6} \mathrm{cc} \mathrm{cm}^{-2}$ respectively for ESS. The volume of spray deposition on top, middle and bottom level leaves of plant was lesser $\left(82.5,64.5\right.$ and $\left.45.3 \times 10^{-6} \mathrm{cc} \mathrm{cm}^{-2}\right)$ in case of ESS than TOG (162.10, 125.60 and $98.50 \times 10^{-6}$ $\mathrm{cc} \mathrm{cm}^{-2}$ ), POK (147.80, 103.40 and $\left.94.80 \times 10^{-6} \mathrm{cc} \mathrm{cm}^{-2}\right)$ and LOK $\left(207.60,184.92\right.$ and $\left.122.11 \times 10^{-6} \mathrm{cc} \mathrm{cm}^{-2}\right)$ respectively. The overall results revealed that percentage spray deposition in case of ESS was significantly $(p=0.022)$ lesser than TOG sprayer $(p=0.041)$, POK sprayer $(p=0.039)$ and LOK sprayer $(p=0.015)$ on top middle and bottom leaves of plant canopy

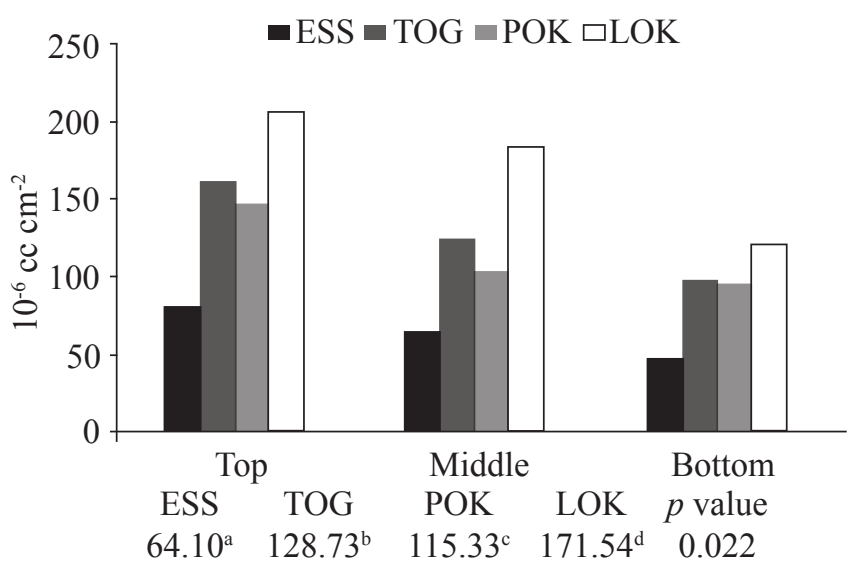

Figure 4: Volume of spray deposition

respectively at $5 \%$ level of significance.

\subsubsection{Bio-efficacy}

On an average insects killed by ESS were significantly $(p=0.00000014)$ higher $85.78,84.80$ and $88.01 \%$, by LOK $(p=0.0016) 35.90,29.74$ and $39.15 \%$, by POK $(p=0.0046)$ $50.99,46.36$ and $37.75 \%$, by TOG $(p=0.0091) 68.05,64.05$ and $57.77 \%$ at 3,7 and 15 days after spraying respectively (Figure 5) at 5\% level of significance. The results showed that insect mortality in case of control was 3.37, -19.88 and $-11.11 \%$ at 3,7 and 15 days after spraying respectively. The negative values depicts that the population of insects after 7 and 15 days of spraying were more than insects population 


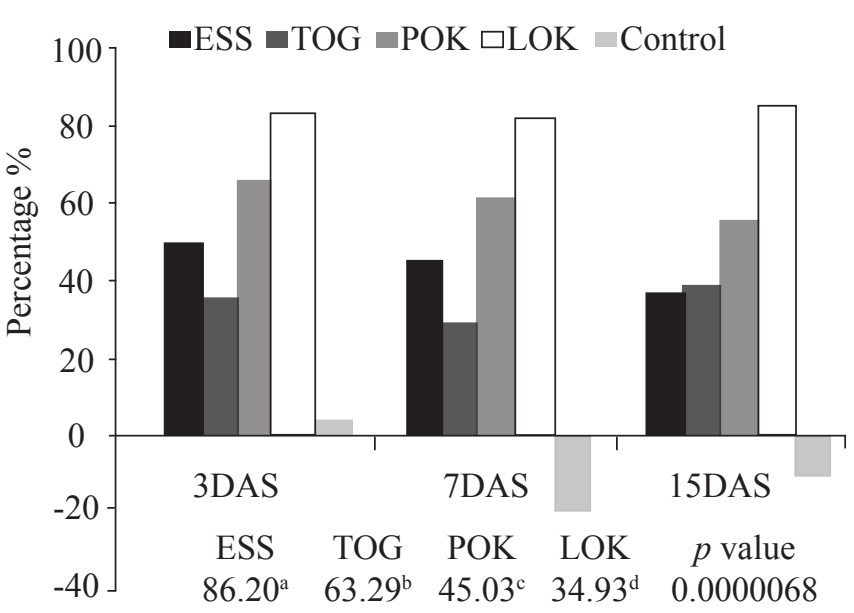

Figure 5: Insect mortality (\%)

counted before spraying. The overall results showed that insects killed by an ESS were $77.91 \%$ higher than control.

\section{Conclusion}

Electrostatic sprayer was efficient at lower value of NMD $(24.48 \mu \mathrm{m})$ and $\operatorname{VMD}(45.28 \mu \mathrm{m})$ with least uniformity coefficient (2.00) compared to all other sprayers. In electrostatic sprayer area covered by droplets $(44.55,55.26$ and $68.68 \%$ ), droplets density $(47.19,68.07$ and $78.26 \%)$ and bio-efficacy $(47.75,59.47$ and $26.57 \%)$ was more as compared to other sprayers (TOG, POK and LOK sprayers respectively). Number of droplets with lowest value of actual diameter was maximum (42 Nos.) in case of electrostatic sprayer.

\section{Acknowledgement}

The authors acknowledge the financial assistance provided by the Department of Science and Technology through the CSIR-CMERI Centre of Excellence for Farm Machinery, Ludhiana, India. The work reported here was conducted as a part of project entitled "Design and Development of an Electrostatic Nozzle for Agricultural Applications".

\section{References}

CCI, 2014. The Cotton Corporation of India Ltd. Available fromhttp://cotcorp.gov.in/current\%ADcotton. aspx? pageid $=4$.

Dhaliwal, G.S., Jindal, V., Dhawan, A.K., 2010. Insect pest problems and crop losses: changing trends. Indian Journal of Ecology 37(1), 1-7.

Graham-Bryce, I.J., 1977. Crop protection: a consideration of the effectiveness and disadvantages of current methods and of the scope for improvement. Philosophical Transactions Royal Society 281, 163-179.

Heijne, C.G., 1980. A review of pesticide application systems. In proceeding of BCPC Symposium- Spraying Systems for the 1980s. ISBN 0901436645, 75-83.

Mishra, P., Singh, M., Sharma, A., Sharma, K., Singh, B., 2014. Studies on Effect of electrostatic spraying in orchards. International Commission of Agricultural and Biosystems Engineering, CIGR Journal 16(3), 60-69.

Narang, M.K., Mishra, A., Kumar, V., Thakur, S.S., Singh, M., Mishra, P.K., 2015a. Field evaluation of manual spraying technology against white flies on cotton crop in south-west Punjab. Agricultural Engineering Today 31(1), 29-33.

Narang, M.K., Mishra, A., Kumar, V., Thakur, S.S., Singh, M., 2015b. Comparative evaluation of spraying technology in cotton belt of Punjab (India). Scientific Journal Agricultural Engineering XL(1), 61-71.

Pimentel, D., Levitan, L., 1986. Pesticides: amounts applied and amounts reaching pests. Bioscience 36, 86-91.

Piche, M., Panneton, B., Theriault, R., 2000. Reduced drift from air assisted spraying. Canadian Journal of Agricultural Engineering 42(3), 117-122.

Singh, M., Mishra, P.K., Ghanshyam, C., Chak, R., 2013. Current status of electrostatic spraying technologyfor efficient crop protection. Agricultural Mechanization in Asia, Africa and Latin America 44(2), 46-53.

Shera, P.S., Arora, R., Singh, P., 2015. Comparative susceptibility of transgenic Bt cotton hybrids to Earias spp. and other non-target insects. Crop Protection 71, 51-59.

Singh, S.K., 2005. Design and development of tractor mountedair-assisted sprayer for cotton. Unpublished Phd. dissertation, Punjab Agricultural University, Ludhiana, India 1-164.

USDA, 2014. United States Department of Agriculture (USDA). Agricultural outlook forum, Friday, February 20, 2015. Available from http://www.usda.gov/oce/ forum/2015_Speeches/Cotton.pdf. 